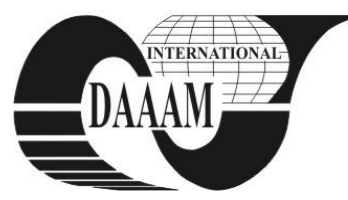

Annals of DAAAM for 2011 \& Proceedings of the 22nd International DAAAM Symposium, Volume 22, No. 1, ISSN 1726-9679 ISBN 978-3-901509-83-4, Editor B. Katalinic, Published by DAAAM International, Vienna, Austria, EU, 2011 Make Harmony between Technology and Nature, and Your Mind will Fly Free as a Bird

\title{
MODEL OF AUTOMATION DEVICE FOR ONTOLOGY
}

\author{
SIR, M[ichal]; BRADAC, Z[denek] \& KACZMARCZYK, V[aclav]
}

\begin{abstract}
The aim of the paper is create ontology for the automation device. The paper summarizes possibilities witch are used for creating the ontology. The first part of paper describes the model of the automation device. The model shows the form of the real automation device with parts witch have to be included. The second part of the paper describes the base of the proposal of the ontology witch is used as the knowledge model for device

Key words: ontology, automation device, SUMO ontology, knowledge
\end{abstract}

\section{INTRODUCTION}

From the historical point of view the ontology is a part of science that has many faces. Originally, ontology was the part of philosophy and was understood as science about "being". Ontology is the universal system of knowledge, which describes objects, phenomena, and regularities of the world. The ontology is a part of science which interests about being and existence. Aristoteles named it as First philosophy.

The ontology allows creating metadata e.g. information about information. We can find ontology in different part of science today. In our case we are taking into account definition for information technology which Gruber described in (Gruber, 1993): „Ontology is explicit specification of conceptualization“

Conceptualization is an abstract model of part of real world, which identifies relevant concept of the part. Explicitly means that it clearly defines type of concept and conditions of its use. The definition is often extended about word "formal". It means that ontology can be computer-processable. The ontology is understated as taxonomy which describes hierarchy of determinate names. As we mentioned in definition of ontology, the ontology is rather connected with information technology today. From the knowledge engineering point of view, the ontology is defined as knowledge model i.e. it is the abstract description of knowledge system.

\section{ONTOLOGY AND INTEROPERABILITY IN AUTOMATION}

Previously in the article we show that the main domain of ontology is the phylosophy. However, if we look around, we find many possibilities to use Ontology in automation.

Ontology is used especially as a knowledge model and on its basis two heterogeneous systems are converted. Another possibility how to use ontology in automation is a decisionmaking method. In this case there would be a decision made based on ontology. For example if control production line based on multiagent systems when the agents share same ontology.

We are interested in language which has been developed specifically to work with sensors data. A SensorML language has been developed by Open Geospatial Consortium. It focuses on processes data visualization on web site because it was designed on XML language structure. SensorML can provide general data about sensor, processing support and measurement analysis. It provides functional properties as accuracy, threshold etc. as shown in (OGC standard, 2005).

\section{AUTOMATION DEVICE AND ONTOLOGY}

The aim of our work is the computer program which works with information from the ontology and methods for detection sensor faults. The program is used to detection of changes in automation device. The computer program uses the ontology as source of knowledge which use to detection of faults.

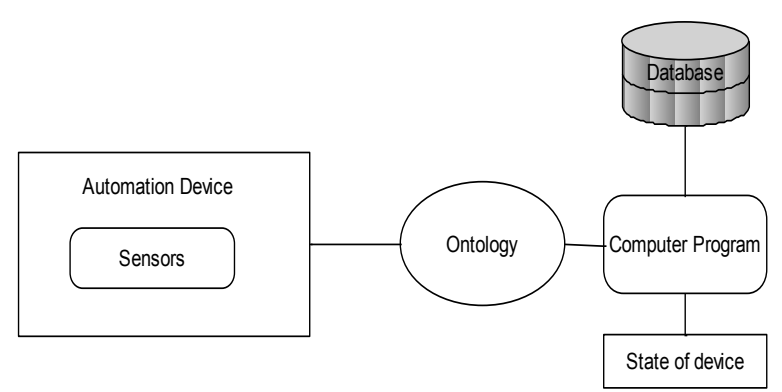

Fig. 1. Concept of our work

\section{DEVICE CONCEPT}

In the field of automation the process data exchange in general is based on real and virtual devices that provide inputs and outputs. The devices are sometimes described by device profile, that restrict device interfaces. However devices in general (in the context of process data exchange), are consisted from:

- Sets of Input/Output values: Set of all process data input/output values and associated attributes that describe the $\mathrm{I} / \mathrm{O}$ value and its quality;

- Sets of other HW modules: Sets of all modules that make up the device;

- Sets of SW modules: Sets of all software modules that make up the firmware of the device;

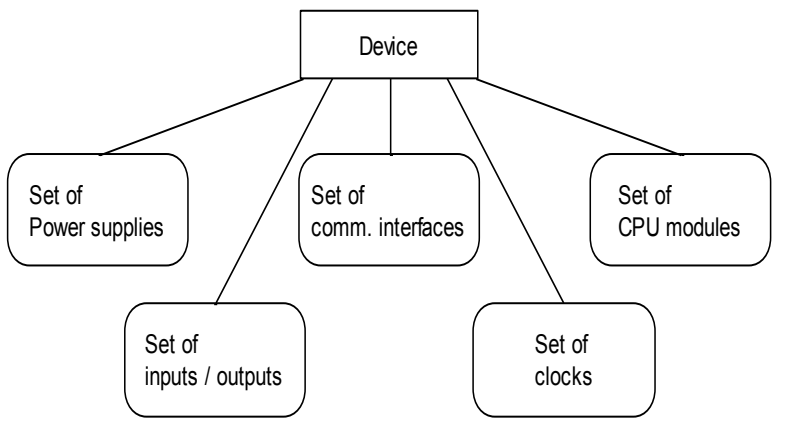

Fig. 2. Concept of an automation device 
Possible concept of a device is shown in figure 2. The input and output channels have to have the same attributes to enable trouble-free sharing of information. It requires equivalent structures at the sender and at the receiver to prevent distortion of information. Proposed concept of an input/output channels, shown in figure 3, consist from:

- Engineering Value: Quantification of the input/output information.

- Validity: Quantification of validity of information stored in the Engineering Value; the validity is gained by evaluation of the status of the provider of the engineering value; this information quantifies truthfulness of the provided information according to the best knowledge of the information provider. Such quantification of truthulness "upgrades" the information exchange to a form of knowledge sharing.

- Timestamp: Timestamp captures time of the measurement; system wide clock synchronization (global system clock) is required for meaningful timestamping.

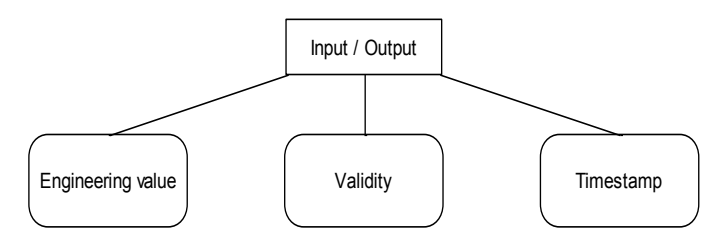

Fig. 3. Concept of an input/output channel

The validity describes to what extent the information provider (sender) believes, that the provided information represents the "truth". It is a crucial element in the concept because it extends the raw information to some form of knowledge. In sensor fusion applications it enables to assign weights to various sources of information (Fielder, 20007).

\section{SOLUTION OF OUR WORK}

The solution for our work is the ontology Ontosensor (Russomanno, 2005). Ontosensor is used for sensor description. Ontosensor creates formal definition of concepts and relations. This ontology expands the IEEE SUMO Ontology as shown in (SUMO ontology, 2011). SUMO ontology is the formal ontology which is the biggest ontology today. SUMO ontology is mapped on WordNet by the authors. The SUMO creates description of the world as we know him.

\subsection{SUMO ontology}

The introduction to SUMO ontology is used in our work. The first part of SUMO ontology, which we use, is figured on figure 8 .

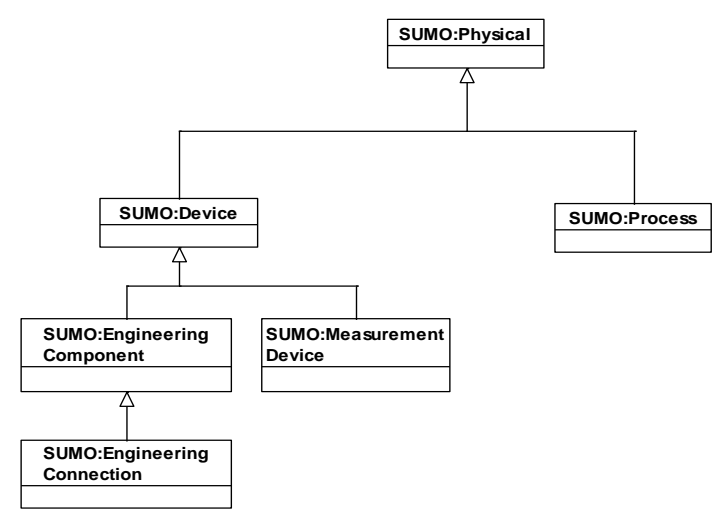

Fig. 4. The parto of the SUMO ontology

The ontology has two parts. The first one is used for description of device. The part is used for assemblage of metadata about the sensor. For example, type of sensor, type of source, information about physical unit etc.

\section{FUTURE WORK}

Our future work is extension of the ontology about influence of the environment where the device works. The solution of the problem is included the uncertainty of the measurement (type B) to the ontology. The uncertainty B includes influences on the measurement.

\subsection{Computer system}

The last part of our work is the computer program which cooperates with ontology and uses the ontology as the source of information. Ontology itself cannot take a decision about the status of the sensor or device. For this reason it is necessary to add a computing system, a program written in $\mathrm{C}$ or $\mathrm{C}++$ language which will operate the data. These information are used as a knowledge about the state of device.

\section{CONCLUSION}

As it was mentioned already above in the article, ontology is domain not only in terms of semantic web today and phylosophy. We are interested in the area of automation and ontology has recently also spread into this field of science.

Based on given ontology examples and especially OntoSensor ontology and its spreading we want to create a system which will contain ontology for automation device. Thanks to computing system and ontology we want to reach the sensor errors detection.

\section{ACKNOWLEDGEMENTS}

This work has been supported in part by Ministry of Education, Youth and Sports of the Czech Republic (Research Intent MSM0021630529 Intelligent systems in automation (VZ UAMT), Grant Agency of the Czech Republic (102/09/H081 SYNERGY - Mobile Sensoric Systems and Network) and grant "Supporting Research of Modern Methods and Approaches in Automation" from the Internal Grant Agency of Brno University of Technology (grant No. FEKT-S-11-6).

\section{REFERENCES}

GRUBER, Thomas R., A translation approach to portable ontology specifications. Knowl. Acquis, Vol. 5, 1993, pp. 199-220, ISSN 1042-8143

OGC 05-086. Sensor Model Language (SensorML) Implementation Specification. Alabama : University of Alabama in Huntsville, 2005-10-05. $110 \mathrm{~s}$

FIELDER, Petr. Interoperability in the industrial automation. Brno, 2005. 116 s. Dizertační práce. Vysoké učení technické v Brně

RUSSOMANNO, David, Sensor Ontologies: From Shallow to Deep Models. IEEE Xplore [online]. 20-22 March 2005 , 5, [cit. 2011-03-22]. WWW: 〈http://ieeexplore.ieee.org/ >. ISSN 0094-2898

Standard Upper Ontology Working Group (SUO WG) Home Page [online]. 2003 [cit. 2011-05-07]. Study Group Knowledge Interchange Format. WWW: $<$ http://suo.ieee.org/index.html> 